\title{
WHEN PULMONARY TUBERCULOSIS REQUIRES RIFAMPCIN THERAPEUTIC DRUG MONITORING: A CASE REPORT
}

V. Burzio ${ }^{1}$, S. Vergnano ${ }^{1}$, J. Bernatoniene ${ }^{1}$, J. Metz ${ }^{1}$, E. Briassouli ${ }^{1}$, E. Chesshyre ${ }^{1}$, I. Ito ${ }^{1}$, M. Roderick ${ }^{1}$, A. Finn ${ }^{1}$

${ }^{1}$ Bristol Children Hospital, Paediatric Infectious Diseases and Immunology, Bristol, United Kingdom

\section{Background}

Tuberculosis remains a major public health issue with 6.3 million new cases reported in $2016,7 \%$ of these in children. Although treatment for fully sensitive tuberculosis is well established, treatment failures are recognised, and optimisation of therapy needs to be considered on an individual basis. We report a case of a treatment failure in a teenager.

\section{Case Presentation}

A 14 years-old Somali girl presented with a 6 week history of fever, productive cough, night sweats and vomiting, not responding to amoxicillin-clavulanate and clarithromycin.
A chest radiography showed an opacity in the left lingual and upper lobe (figure 1).

Figure 1. Chest radiography at onset

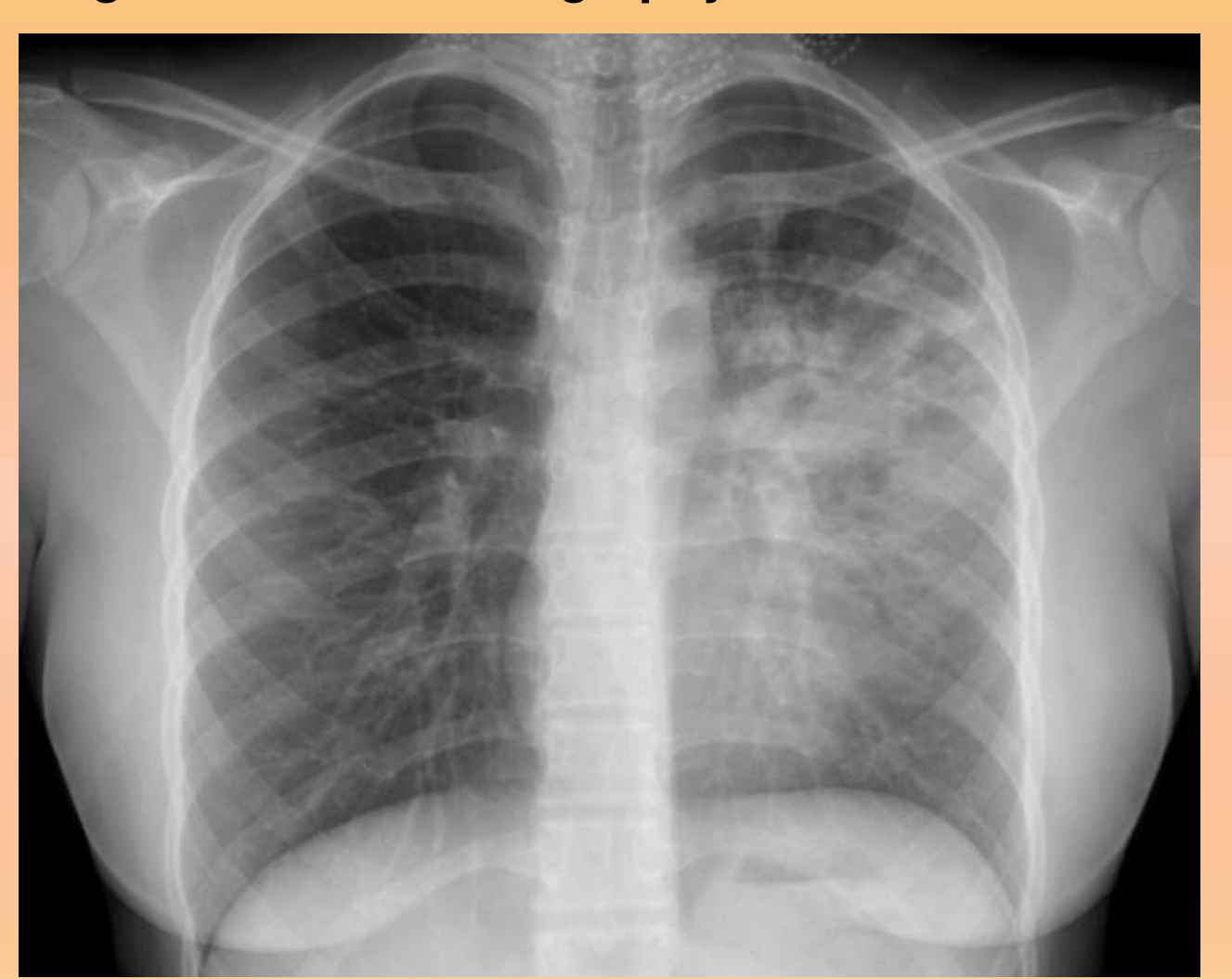

The sputum smear resulted positive for acid fast bacilli and grew fully sensitive Mycobacterium tuberculosis (TB). She was started on quadruple TB therapy at standard dose.
After initial improvement, at six weeks of therapy she represented with dyspnoea, hematemesis, and night sweats. Her chest MRI showed progression of the disease (figure 2). Directlyobserved therapy was initiated but the urine colour did not turn orange. Therapeutic drug monitoring (TDM) for rifampicin was requested and was very low (table 1).

Figure 2. Chest MRI, t2 sequence

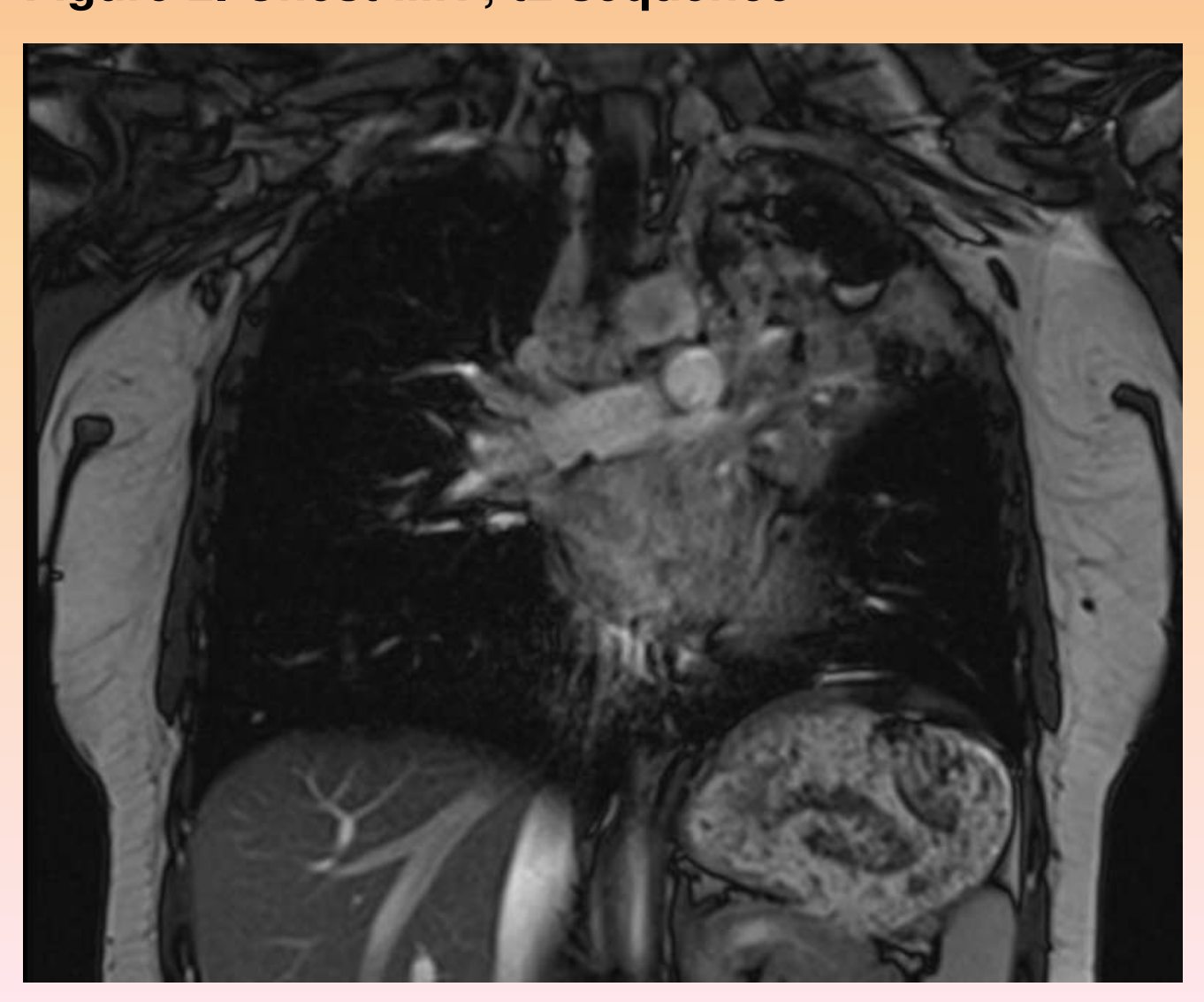

Table 1. TDM for Rifampicin

\begin{tabular}{|c|c|l|}
\hline Levels & Patient & Reference \\
\hline Pre-dose & $<0.3$ & $\begin{array}{l}\text { Pre }<0.5 \mathrm{mg} / \mathrm{L} \\
\text { Post }<4 \mathrm{mg} / \mathrm{L} \\
\text { sub- } \\
\text { therapeutic } \\
\text { Post } 4-8 \mathrm{mg} / \mathrm{L} \\
\text { usually } \\
\text { adequate } \\
\text { Post } 8- \\
\text { dose }\end{array}$ \\
\hline $\begin{array}{c}2 \text { hours post- } \\
\text { dose }\end{array}$ & $4.7 \mathrm{mg} / \mathrm{L}$ ideal \\
\hline $\begin{array}{c}4 \text { hours post- } \\
\text { dose }\end{array}$ & 4.1 & \\
\hline
\end{tabular}

\section{Discussion}

A patient not responding to anti-TB treatment should be evaluated for poor adherence, drug-resistance, complication of pulmonary TB and lung disease from other causes. Rifampicin is one of the key drugs in the treatment of tuberculosis and optimising the dose is essential for successful treatment ${ }^{1}$. 